CURRENT RESEARCH JOURNAL OF PEDAGOGICS 2(11): 96-103,

November 2021 DOI: https://doi.org/10.37547/pedagogics-crjp-02-11-19

ISSN 2767-3278

(C)2021 Master Journals

Crossref doi) 81 Google

Accepted 25th November, 2021 \& Published 30 ${ }^{\text {th }}$ November, 2021

\title{
MATHETICO TRANSDISIPLINARY BASES OF INNOVATION IN EDUCATION
}

\author{
Yulduzkhon Kulnazarovna Kushnazarova
}

Lecturer, Chirchik State Pedagogical Institute, Uzbekistan

\section{ABSTRACT}

Global paradigms "cover all types of activity and underlie the shift from the deterministic stochastic and to the third synergetic paradigm." The paradigm can be described using three keywords: self-organization, open systems, non-linearity. This work uses the data tabulation method and the graphical presentation of the results.

The philosophy of postmodernism is a motor speech between a person and his reality. The value of education is not to memorize facts, to encourage the brain to think. In other words, postmodernism is "a new model of thinking that refuses to embrace traditionalism without reflection and reappraisal." In postmodernism, all similar, different and non-traditional data and knowledge coexist. Thus, if in modernism educational services are important, if they are useful, then in postmodernism the usefulness of a product or service is determined by the emotions of the person for whom the product was created. From this point of view, the educational product and service should be memorable.

KEYWORDS:- Pedagogy, mathematics, pradigma, philosophy, education, modernization, modernization, analysis, teaching.

\section{INTRODUCTION}

\section{Transdisciplinary Approaches in Education}

The term "transdisciplinarity" was first proposed by J. Piaget in discussions with E. Jantsch and A. Lichnerowitz in the framework of the international working group "Interdisciplinarity - Teaching and Research Programs at Universities". According to J. Piaget, transdisciplinarity is the third and highest level in the system of integrating knowledge, following interdisciplinarity - a form of interaction of various disciplines focused on interchange and mutual enrichment, and multidisciplinarity - combining disciplines to solve a problem without structural changes scientific discourse The specificity of this stage is in overcoming the limitations of interaction between researchers and determining the location of these connections "in a common system without stable boundaries between disciplines"

Discussion of problems and, above all, the prospects of education marked the next stage in the development of transdisciplinarity, associated with the symposium "Science and the boundaries of knowledge: a prologue of our cultural past" (Venice, Italy), which brought together researchers and teachers from different countries of the world under the auspices of UNESCO. Particular attention in the text of the "Venice Declaration" was paid to the contradictions between science and other forms of knowledge, in connection with which the need for a constructive "epistemologically unbiased" dialogue of cognitive practices that make up a holistic experience of human cognition was 
CURRENT RESEARCH JOURNAL OF PEDAGOGICS 2(11): 96-103,

November 2021 DOI: https://doi.org/10.37547/pedagogics-crjp-02-11-19

ISSN 2767-3278

(C)2021 Master Journals

Crossref do: 81 Google

Accepted 25th November, 2021 \& Published 30 ${ }^{\text {th }}$ November, 2021

emphasized. Undoubtedly, the main factor in increasing attention to the possibilities of integrating various cognitive strategies was the scale of the emerging problems, which requires an effective methodology of cognition and action. In the dialogue started at the conference, its participants saw the starting point for the further development of transdisciplinary approaches commensurate with the global problematic, presented by B. Nikolescu in the "Workbooks" of the conference

To date, the possibilities of transdisciplinary approaches in solving complex socially significant problems in education and in other spheres of the life of society have become the object of theoretical comprehension in several concepts of philosophy and sociology of science. And various interpretations of the phenomenon of transdisciplinarity in the most complete form were conceptualized by the American researcher J. Klein The first approach, according to Klein, is associated with the development of "complex" thinking and the expansion of the established image of science. Its most illustrative example is the activities of the International Center for Transdisciplinary Research (CIRET), founded by the Romanian physicist B. Nicolscu in 1987 in Paris.

The second vector reveals the relationship of transdisciplinarity with a critical assessment of terms, concepts and methods, which, by transgressing disciplinary boundaries, can be considered as means of a higher level of reflection. It is in this vein - a transgressive shift beyond the hermetic boundaries of disciplinary knowledge and the achievement of deeper reflexivity - that the ideas of transdisciplinarity are developed by Dölling and Hark The third approach focuses on expanding the interpretation of the synthetic paradigm proposed at the first conference "Interdisciplinarity: Problems of Teaching and Research in Universities", and pushes away from the ideas of the integrity of knowledge, the need to reorganize existing theoretical attitudes. In the most obvious form, this trend can be seen in the direction designated by North American scientists in cancer research as "transdisciplinary science". The formation of transdisciplinary science is due, in the minds of its theorists, to the pooling of interdisciplinary resources in a single methodological and theoretical framework, including a wide range of issues related to social, political, environmental and other possible factors that have a particular impact on the health and well-being of an individual and society as a whole. The fourth line is a kind of "trans-sector of transdisciplinarity", which took shape at the turn of the 1980-1990s. in Germany and Switzerland when considering environmental issues. Its key indicator is special attention to the sphere of the life world, which implies the relevance of the problematics to societal parameters and the involvement of the knowledge and experience of stakeholders in the methodological framework of research (from the English stakeholder; literally. interested social actor).

The ideas of this approach are well represented in the theoretical and practical developments of the "Swiss school" of transdisciplinarity, focusing on identifying mechanisms of interaction between the academic community, industry and the business sector, aimed at harmonizing interests in three interrelated aspects: 1) determination of production goals for the industrial sector, 2) identification of priorities for the development of innovative technologies, 3) inclusion of stakeholders in the design and implementation of results. In this perspective, transdisciplinarity is viewed as a resource for synergy between expert (academic) and everyday (non-professional) types of knowledge in solving problems associated with sustainable development and the risks of technological modernization. 
CURRENT RESEARCH JOURNAL OF PEDAGOGICS 2(11): 96-103,

November 2021 DOI: https://doi.org/10.37547/pedagogics-crjp-02-11-19

ISSN 2767-3278

(C)2021 Master Journals

Crossref do: 81 Google

Accepted $25^{\text {th }}$ November, 2021 \& Published $30^{\text {th }}$ November, 2021

The main emphasis in our interpretation is placed on the philosophical reflection of the problems of modern science, the main focus of which could be formulated as follows. To respond positively to the challenges of the time, to rethink the established understanding of the state of modern philosophy and science as a crisis, to identify previously unclaimed resources of the methodology of scientific cognition, capable of overcoming its boundaries consecrated by tradition. This concerns, by and large, the creative solution to the problem of "two cultures" (contact interaction of natural science and socio-humanitarian knowledge) in the context of conceptualizing post-nonclassical practices. philosophical reflection on the problems of the transdisciplinary approach, which, while retaining the classical interpretation of the subject-object relationship as a starting point, gives it a different one, a more complex interpretation of the subject of scientific research, which is associated with the sociohumanitarian dimension of its problematization. The latter entails, in turn, the interval interpretation of classical oppositions, for example, such as fundamental and applied, universal and concrete, normative and descriptive, etc. Recursive cyclical nature of justification methods, depending on the contingent agreement of the opinions and actions of the actors involved in the discussion and solution of the problem. The philosophy of transdisciplinarity, as a rule, deals with the complexity of existential problems and ways of not only researching them, but also teaching the practical development of transdisciplinary experience as a personal perspective of behavior in an actual situation .

\section{Transdisciplinary Approaches in Education}

As noted, the term "transdisciplinarity" first appeared in the context of the discussion of educational problems within the framework of the international working group "Interdisciplinarity - teaching and research programs in universities", where Piaget anticipated the formation of a new stage. The prediction made more than forty years ago about the prospects for the introduction of research and educational transdisciplinary programs in universities today finds its convincing confirmation .

The text of the "World Declaration on Higher Education for the 20th Century the text of the "World Declaration on Higher Education for the 20th Century: Approaches and Practical Measures" adopted by the participants of the UNESCO International Conference on Higher Education indicates the need to introduce transdisciplinary approaches into educational programs for training future specialists to solve complex problems of nature, person and their relationship. Thus, the appeal to the possibilities of transdisciplinarity can be considered as the basis for the "progressive shift of problems" of modern education, consonant with the refusal to build one-dimensional models of the multidimensional world, the emergence of new dimensions of science and the development of an innovative culture.

Approaches and Practical Measures" adopted by the participants of the UNESCO International Conference on Higher Education indicates the need to introduce transdisciplinary approaches into educational programs for training future specialists to solve complex problems of nature , person and their relationship. Thus, the appeal to the possibilities of transdisciplinarity can be considered as the basis for the "progressive shift of problems" of modern education, consonant with the refusal to build one-dimensional models of the multidimensional world, the emergence of new dimensions of science and the development of an innovative culture.in the text of the "World Declaration on Higher Education for the 20th 
CURRENT RESEARCH JOURNAL OF PEDAGOGICS 2(11): 96-103,

November 2021 DOI: https://doi.org/10.37547/pedagogics-crjp-02-11-19

ISSN 2767-3278

(C)2021 Master Journals

Crossref do: 81 Google

Accepted 25 $5^{\text {th }}$ November, 2021 \& Published 30th November, 2021

Century: Approaches and Practical Measures" adopted by the participants of the UNESCO International Conference on Higher Education , it is indicated the need to introduce transdisciplinary approaches into educational programs for training future specialists to solve complex problems of nature, man and their relationship. Thus, the appeal to the possibilities of transdisciplinarity can be considered as the basis for the "progressive shift of problems" of modern education, consonant with the refusal to build one-dimensional models of the multidimensional world, the emergence of new dimensions of science and the development of an innovative culture.

Leave from Along with a complex of internal factors in the system of higher education, the key determinants of the development of transdisciplinary strategies in education and educational policy were external causes associated with interethnic, religious, geopolitical conflicts, uneven dynamics of civilizational development, an imbalance between the intensification of economic growth and extension. ssive models of social structure,. "The modern era - wrote at the turn of the XIXXX centuries. the founder of social psychology, G. Le Bon, is one of such critical moments when human thought prepares for change. There are two main factors behind this change. The first is the destruction of the religious, political and social beliefs that gave rise to all elements of our civilization; the second is the emergence of new conditions of existence and completely new ideas, which were the result of modern discoveries in the field of science and industry".

However, the current crisis is unfolding in the space of new communication and information opportunities, glocalization and globalization processes, acute environmental and energy problems, demanding not palliative measures, but a holistic program of reformatting the cornerstones of modern technogenic civilization.
From this point of view, the phenomena observed in education, namely, a narrow specialization in teaching disciplines, the absence of integral worldview and value guidelines are symptoms of systemic crisis processes.. For their solution, they are forced to take into account the paradigmatic changes in science, new conditions for the relationship between man and nature, the exponential and poorly controlled growth of new technologies, the expansion of the information space.

Of course, the consequences of stating the severity of the situation should be transformed into real practical actions that have at least two essential aspects for their implementation. First, the introduction of transdisciplinarity in education can be understood as teaching a separate subject with the inclusion of transdisciplinary approaches, through contextualization and the establishment of interdisciplinary connections. Второй, интеграция трансдисциплинарности того или иного учебного заведения в целом.

This area of research and development is quite new, but, nevertheless, some experience has already been accumulated, demonstrating a heuristic resource for the implementation of transdisciplinarity in programs of higher and postgraduate education. As an example, we can point to the course "Transdisciplinary Studies" of the Faculty of European Studies of the BabesBoyai University in Cluj-Naboka (Romania), the program of transdisciplinary studies of sustainable development for post-graduate education at the University of Stellenbosch (South Africa), as well as the activities of the Institute ethics and transdisciplinary research of sustainable development "Loifan" of the University of Lunenburg (Germany). However, regardless of the chosen strategy for organizing transdisciplinary education, we are talking about an unconventional approach aimed not only at the transfer of knowledge, but also at joint 
CURRENT RESEARCH JOURNAL OF PEDAGOGICS 2(11): 96-103,

November 2021 DOI: https://doi.org/10.37547/pedagogics-crjp-02-11-19

ISSN 2767-3278

(C)2021 Master Journals

Crossref do: 81 Google

Accepted 25th November, 2021 \& Published 30 ${ }^{\text {th }}$ November, 2021

creative research focused on various cognitive resources, case analysis and successful experience in solving similar problems. ... All this requires an adequate understanding of the complex of issues with which the professional activities of future specialists will be associated, the relationship of real substantive practice with the social context.

can be formulated following E. Moren as follows: "how to get access to information about the world and how to form the ability to consistently present and organize this information? How to perceive and understand the Context, Global (the relationship of the whole and parts), Multidimensional, Complex? ".

The French researcher connects the answers to the questions posed.In the conditions of the permanent expansion of channels and the volume of information, one of the key tasks with the paradigmatic reform of thinking and the approval of cholistic tendencies in cognition and education. This presupposes the ability to correlate the problem with its context, while contextualization, being one of the sides of integrative strategies, the ability to think nonlinearly and holistically, can reach a global scale. A measure of the adequacy of the selected change algorithms is the ability of education to take into account the multidimensionality of the world's phenomena, taking into account the mobile matrix of rapidly changing reality. In this context, the optics of the transdisciplinary approach is consistent with the reasoning of $\mathrm{B}$. Pascal, since. "... everything is mutually supported by a natural and elusive connection that connects the most distant and different things, then I consider it impossible to know the parts without knowing the whole, as well as knowing the whole without detailed acquaintance with the parts"

Therefore, a person, society and culture are revealed in a wide range of interactions and interrelationships, forming a complex and changing system of relations of personal priorities and motivations, social institutions and cultural valuesIt is clear that the order of these relationships, while maintaining stability in its development, must react and permanently adjust itself anew, proceeding from the uniqueness of the situation "here and now". Moreover, the search for models adequate to nonlinear projections of the modern world is impossible without understanding the problem of complexity, which includes the interaction between the "object of cognition and its context, parts and the whole, whole and parts, parts among themselves... Therefore, complexity is the connection between unity and plurality ". The latter initiates the task of developing the "general ability of thinking", which includes the ability to understand the complex, context, multidimensionality and global relations".

A practical question arises of how to instill a skill, to form an ability, proportioning the student's natural data with the conditions above the set task. The closest answer, requiring further clarification and concretization, may be the development of an appropriate culture and "policy of academic politeness" (J. Klein), which are equally important for scientists and teachers, as well as for administrators from education and science. The formation of true professionalism is impossible without liberation from the dictates of templates, as well as the development of the ability to contextualize, correlate the "complex", multidimensional and global in a specific transdisciplinary event. In such a situation, effective guidelines for action are in demand, as, for example, the principles of learning to learn, learning to do, learning to live together and learning to exist, proposed by the international commission under the leadership of

J. Delors in the UNESCO Report "Education for the 21st Century" .. 
CURRENT RESEARCH JOURNAL OF PEDAGOGICS 2(11): 96-103,

November 2021 DOI: https://doi.org/10.37547/pedagogics-crjp-02-11-19

ISSN 2767-3278

(C)2021 Master Journals

Crossref do) 81 Google

Accepted 25th November, 2021 \& Published 30 ${ }^{\text {th }}$ November, 2021

, "Learn to learn." The acquisition of the ability to learn can be understood both as a means and as an end of human existence. In the first case, we are talking about the development of effective skills that open up for the individual, along with new knowledge, new horizons of professional and personal realization, as well as communicative spaces. From a targeted point of view, "learning to learn" means gaining the joy of discovering something new, which begins with wonder. Another significant aspect is revealed in the ability to distinguish between demanded and actual knowledge from illusory pseudoscientific cognitive constructions, as well as to find the correct landmarks in the information ocean. received in the educational process, and personal initiative, a willingness to learn and change. Those who have creative potential, creative thinking, the ability to handle large amounts of

The next dialogue and the search for compromise solutions. Thus, teachers are faced with the task of forming a new communicative culture necessary to "live together" in an open and spiritually healthy space of dialogue. «Учиться существовать». Это принцип продолжает идеи известного доклада Э. Фора «Учиться существовать». 1972), which clearly expressed concern about the prospects of negative effects of dehumanization due to the acceleration of scientific and technological progress The symmetrical response of education to the forced dynamics of technoscience should be an approach that allows to reduce the risks of imbalance of technogenic and spiritual in civilizational development, and therefore to balance the technocentrism of our time with humanistic, aesthetic, moral and social dimensions At the heart of modern educational and upbringing strategies should be a holistic approach based on the recognition of the uniqueness of the personality of each student or student with talents both in the scientific and technical or natural science spheres, and in the fields of artistic creativity.

At the heart of modern educational and upbringing strategies should be a holistic approach based on the recognition of the uniqueness of the personality of each student or student with talents both in the scientific and technical or natural science spheres, and in the fields of artistic creativity Explication of the problems of modern education in the optics of an innovative approach is perhaps the most discussed topic of recent times. The appeal to the innovative potential of transdisciplinarity is of interest from the perspective of the theoretical constructions of the "knowledge society" and "learning society". As the authors of UNESCO's Towards Knowledge Societies report emphasize: “...

When old models are being challenged by ever more rapid changes and when 'learning by doing' and the ability to innovate become increasingly important, the cognitive dynamics of our societies has become a major challenge" . Changing the role of knowledge in a society, the main parameters of which are tuned to the development of new assets and resources, presupposes the formation of an innovative culture..

In the context under consideration, the innovative culture breaks away from the narrow scientific and technical interpretation of civilizational development, referring to the possibilities of social, humanitarian, educational, etc. innovation. The latter not only determine the real prerequisites for the necessary sociohumanitarian support of technoscience, capable of resisting the "traps" of short-term economic interests, but also act as conditions for rethinking the value imperatives of culture.. The other side of the indicated contradictions is associated with the time horizon and in general can be formulated as follows: "How to ensure the alignment of the goals and practices of education 
CURRENT RESEARCH JOURNAL OF PEDAGOGICS 2(11): 96-103,

November 2021 DOI: https://doi.org/10.37547/pedagogics-crjp-02-11-19

ISSN 2767-3278

(C)2021 Master Journals

Crossref do: 81 Google

Accepted 25th November, 2021 \& Published 30 ${ }^{\text {th }}$ November, 2021

with the long-term interests of innovative and sustainable development." The relevance of transdisciplinarity to the multiplying demands of an innovative culture is seen, first of all, in the life of the "scientific superorganism" - consortia of scientific and educational centers and universities, transprofessional structures of hybrid groups, associations of expert communities - creating "road maps" of our time Playing one of the key roles in the "triple spiral of innovation" (state-industry-universities), the higher education system is forced to respond quickly to new modalities of knowledge production, take into account the changing images of the future, provide a certain space of freedom and creativity, thereby, overcoming the inevitably arising contradictions between the attitude towards radical novelty and the existing limitations of the social institutions of science and education. Interaction of the mentioned social actors in the new combinatorics of network structures of the "triplex of innovations" (L.P. Kiyashchenkoaffects the transinstitutionalized matrix that forms the behavior of real agents of innovation. The ethos of modern science, in contrast to its classical interpretation, manifests itself in the interval between: a) the idea of common ownership and private ownership of knowledge (for example, in the form of patents); b) the universalism of the objective observer and the particularism of the included; c) scientific disinterest and disinterestedness of the scientist and interest in obtaining a practically useful effect; d) organized skepticism of objective science and organized dogmatism of a commercially oriented one, these oppositions form a network of intervals.

Depending on the proposed circumstances, they work due to contextually: either as an integrating or as a disintegrating principle in the organization of the transdisciplinary community Within which [intervals] a specific act is performed in the transversal (ie, beyond the accepted norm for the adequate expression of a specific case situation). In other words, the boundaries of normativity acquire a dynamic contingent character, begin to depend on the goals set by the transinstitutional community and each of its individual participants.

Thus, the possibilities and prospects for the implementation of transdisciplinary approaches in education are revealed in solving a two-fold task: on the one hand, the development of the most effective goals and ways to meet the increasingly complex challenges of time, and on the other hand, the formation of a personality capable of "Creative destruction" and responsible creation.

\section{REFERENCES}

1. Prigogine I., Stengers I. Order from chaos. A new dialogue between man and nature. M .: URSS, 2003.

2. Morin E. Method. Nature of Nature. M .: Progress - Tradition, 2005.

3. Laszlo E. Age of bifurcation: comprehension of the changing world // Path. 1995. No. 1.

4. Morin E. Mes Demons. Paris: Stock, 1994.

5. Grebenshchikova E.G. Ethos of "postacademic" science and the transformation of moral imperatives of knowledge production // Integration of education. 2012. - No. 1. - with. 33-38.

6. Kiyashchenko L. P., Mirskaya E.Z. The ethos of science in an era of change // Ethos of science. M .: Academia, 2008.

7. Kiyashchenko L. P. Ethos of postnonclassical science // Ethos of science. M $\therefore$ Academia, 20UNESCO on the World Conference on Higher Education Higher Education in the Twenty- First Century: Vision and Action. [Electronic resource]. 
CURRENT RESEARCH JOURNAL OF PEDAGOGICS 2(11): 96-103,

November 2021 DOI: https://doi.org/10.37547/pedagogics-crjp-02-11-19

ISSN 2767-3278

(C)2021 Master Journals

Crossief do) 88 Google

Accepted 25 $5^{\text {th }}$ November, 2021 \& Published 30 ${ }^{\text {th }}$ November, 2021

URL: http://www.unesco.org/ education / educprog / wche /

8. переводов, например, для технических терминов, которые должны быть в будущем включены в обновления системы перевода. Википедия

9. ChromeMorin E. Seven complex lessons in education for the future. UNESCO, 1999. 10. Pascal B. Thoughts. [Electronic resource]. URL: http://www.vzms.org/pascal.htm

10. Learning to be: the world of education today and tomorrow. UNESCO, 1972. [Electronic resource]. URL: unesdoc.unesco.org/images/0000/00001 8/001801e.pdf

11. UNESCO World Report Towards Knowledge Societies. [Electronic resource]. URL: http://unesdoc.unesco.org/images/0014/ 001418/141843r.pdf

12. Kiyashchenko L.P. The triple helix of transdisciplinarity in the knowledge society // Horizons of humanitarian knowledge. Moscow: GITR, 2011. 